\title{
Research on Promoting Visual Communication of Local Folk Culture by Using Digital Technology
}

\author{
Zhixiong Jia and Yingfa Yang (iD \\ School of Marxism, Hebei University of Engineering, Handan, Hebei 056038, China \\ Correspondence should be addressed to Yingfa Yang; yangyingfa@hebeu.edu.cn
}

Received 21 November 2021; Accepted 27 December 2021; Published 20 January 2022

Academic Editor: Baiyuan Ding

Copyright (c) 2022 Zhixiong Jia and Yingfa Yang. This is an open access article distributed under the Creative Commons Attribution License, which permits unrestricted use, distribution, and reproduction in any medium, provided the original work is properly cited.

\begin{abstract}
Through the visual analysis of local customs and cultures by using digital technology, the total index of digital artificial intelligence, the environmental support of artificial intelligence (AI), and the competitiveness of AI industry have developed well, while the creativity of AI knowledge has developed steadily. According to the survey of digital technology audience education, it can be seen that the respondents with high school to undergraduate education have a higher audience rate of digital technology, while those with other academic qualifications have a lower audience rate, so digital technology can be popularized through education. Through the investigation of audience jobs, it is known that most of the audience of digital technology are engaged in enterprise staff, but they are less exposed to digital technology in political party organs. It can be seen that the loading time of visual images after clustering processing will be reduced by about 200 compared with that without clustering processing, which greatly improves the efficiency of visual graphics loading. As well as the analysis of the development of visualization, we can see that from the sixteenth century to the present, the visualization efficiency has increased from about $50 \%$ to $98 \%$, which greatly improves the efficiency. According to the survey of local folk customs, from 2013 to 2019, local residents' awareness of local folk customs has been continuously improved, from $30 \%$ to about $48 \%$, while the awareness of completely unclear folk customs has dropped from $10 \%$ to about $1 \%$. Through the investigation of local folk culture, it can be seen that in the promotion of local folk culture, the governance system and measures are insufficient, and the governance effect cannot be effectively fed back.
\end{abstract}

\section{Introduction}

Through the use of digital technology to visually analyze the local folk culture, we know that there are some problems in the development of local folk customs, such as imperfect governance system and feedback system. We should improve the related problems and promote the protection, development, and inheritance of local folk culture.

Literature [1] realizes data transmission to memory by constructing a new meteor radar. In order to construct this kind of meteor radar, it is necessary to combine modern digital technology with computer method so that it can be realized, and the relevant position of meteor shower radiation source can also be inferred by this meteor radar. In order to apply the new digital technology in literature [2], economists put forward three explanatory methods to explain the paradox related to productivity. In this paper, generative pretrained transformer (GPT) technology and economic system transition method are used to understand these three effects. Literature [3] investigates 1234 educators and investigates the internal and external influencing factors of digital technology on educators through research path modeling. The results of this study show that digital technology has a great influence on educators and children's learning, and this digital technology can also improve teachers' teaching confidence and help teachers' classroom teaching. Literature [4] congress reformulated two schemes to protect copyright and creative works. To address the threat posed by digital technology, congress enacted the Digital Millennium Copyright Act (DMCA) to enable authors to protect their works. It may be unwise for the DMCA to prohibit the use and distribution of decryption 
technology, but it also aims to reduce the impact of digital technology on copyright. Literature [5] provides an analytical framework to understand the development from e-marketing to mobile marketing. Through analysis, we realize that its growth is ultimately due to the growth of technology, including the performance and power of digital technology and the development of the times. These are the factors of marketing growth. With the development of the times, many children are also using network technology [6]. In order to study the experience of children and families in using new technologies such as mobile phones, tablets, computers, and other digital technologies, different countries are studied. Its research structure provides children and families with suggestions on the use of digital technology. Literature [7] studies single event reversals for testing heavy ions and protons. In this study, heavy ion and proton test structures showed that many cells were disordered and no latch-up phenomenon was observed. It is proved that charge sharing is a mechanism of multiunit flipping. Literature [8] manages the process of laboratory or network by combining digital technology management with printing technology, so as to effectively handle image input and workflow. Improve efficiency, thus reducing the requirement of physical batch processing. Therefore, the laboratory can effectively handle the relevant workflow. Literature [9] is a representative folk culture with vivid and diverse forms of expression. At the same time, it can best reflect the local folk customs and also has the development route of keeping pace with the times. Local folk culture is the concrete expression of cultivating local people's social value, which has very important educational significance and is a good embodiment of social value. Literature [10] shows that the local traditional folk culture is often formed by the collision, absorption, and acceptance of various customs and cultures through Professor Zhao Zongfu's related works. It exposes the unique and distinct regional customs and culture. Academy is the experience of famous customs and culture [11]. Through the study of academy, new ideas can be effectively disseminated through academy, and it is also helpful for the early introduction of new ideas. Academy is also a gathering place of intellectuals, which embodies the secular and down-to-earth development of people's daily life. It plays an important role in the introduction of new ideas. This paper takes the Snowtown Festival in Lhasa as the research object, and through analysis [12], it is known that this custom culture can protect and activate the local traditional culture. We should also attract the public's interest in local customs and cultures through customs and cultures and actively participate in traditional customs and cultural activities to promote the better development of customs and cultures. In order to study the signal transmission of neural connections in visual cortex, literature [13] can study the optical imaging of neural activity in rat cortex, which has the advantage of high spatial and temporal resolution. From this study, we can know that excitation is at least partially transmitted horizontally through vertical connections between neurons. Literature [14] focuses on the concept of learning vision in the process of knowledge transfer, which has become the most active research field at present. In order to explore the cross-category learning process, we can study the algorithm through cross-category tags, through which we can realize the knowledge dissemination between the source category and the target category and prove the effectiveness of this method. Literature [15] shows the intrinsic optical signals of frog retinal slices, which can work together by measuring different types of retinal neurons at the same time. Although the light sensing layer IOS is mainly limited to visible light, the inner retinal IOS has a characteristic near-to-far time history. Through the contents of the above literature, we find that the research points of traditional culture are more prominent, without using relevant research techniques and strategies for in-depth analysis. However, the application of digital technology is still analyzed in the relevant framework, and the visualization technology of traditional culture can further show the specific methods described in the article, and the visualization realizes the communication of folk culture and provides a suburban way.

\section{Visual Analysis of Folk Customs with Digital Technology}

2.1. Digital Development Status. Common digital technology types: application programming interface (API), artificial intelligence, big data, cloud computing, Internet of things, mobile technology, 5G technology, blockchain, etc. [16].

2.1.1. Digital Technology Artificial Intelligence. The artificial intelligence of digital technology operates individual-data behavior data by accumulating individual data; AI learns simulation and makes decisions for it. Through individualbehavior data, AI simulates group behavior and individual behavior. Finally, individual operation is carried out through individual behavior and group behavior [17]. Flow chart of artificial intelligence is shown as Figure 1.

The three modules are divided into individual data accumulation, AI learning simulation, and decisionmaking module. Accumulating individual data is to realize data collection module, and using the model needs enough data sets; the AI learning model simulates the collected data set to obtain the corresponding feature attributes; the decision-making module is to achieve the above simulation characteristics for decision-making results and give specific decision-making conclusions for the corresponding results.

2.1.2. Digital Technology Cloud Computing. Digital technology carries out basic features, development models, service models, and other computing models through cloud computing. The basic features include quick response and customized service. The development model includes private, public, community, and ecological aspects. Service model includes software, platform, infrastructure, and other services. Cloud computing is through digital technology to improve the computing efficiency of cloud computing-related models. Digital technology cloud computing diagram is shown as Figure 2. 


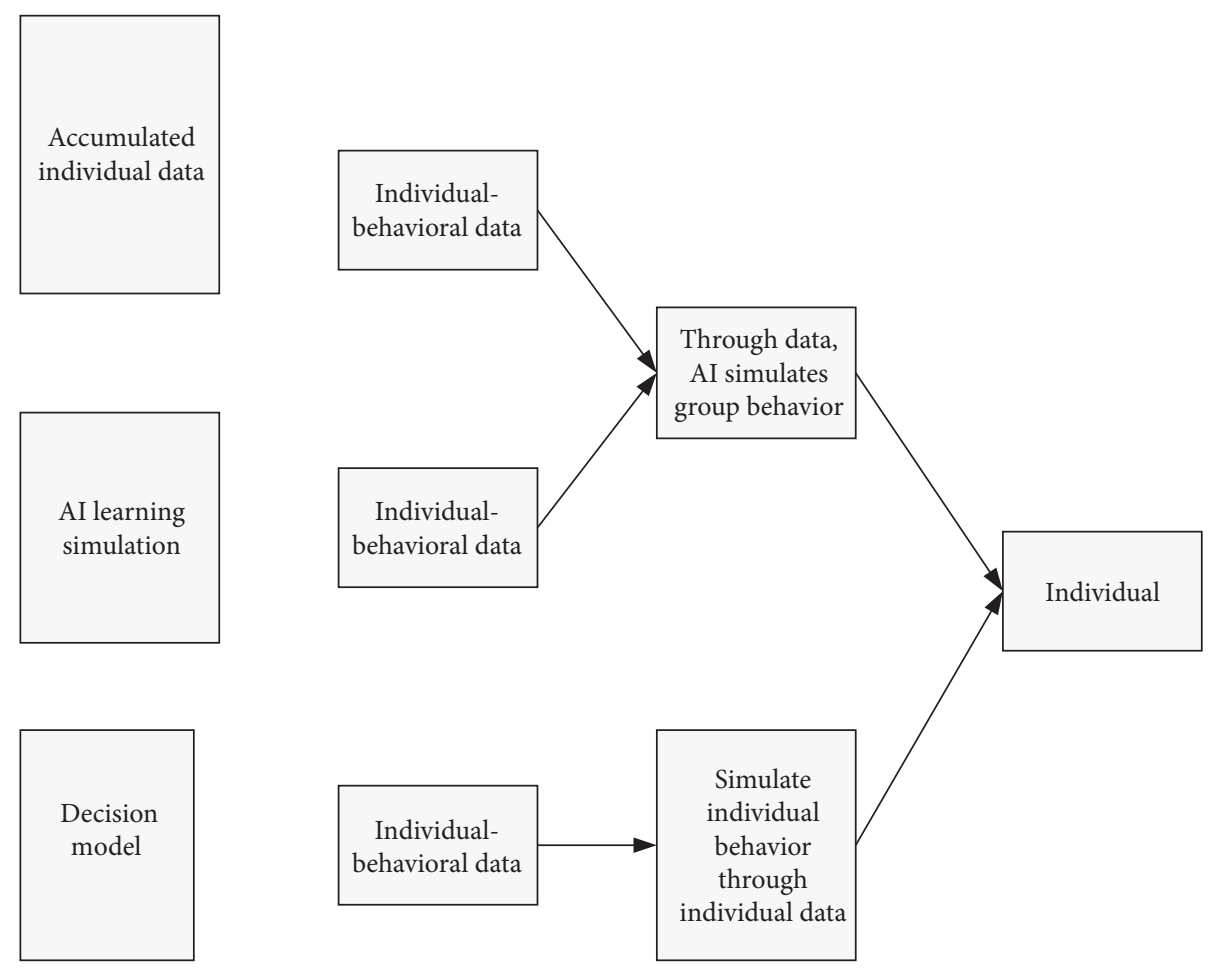

FIgURE 1: Flow chart of artificial intelligence.

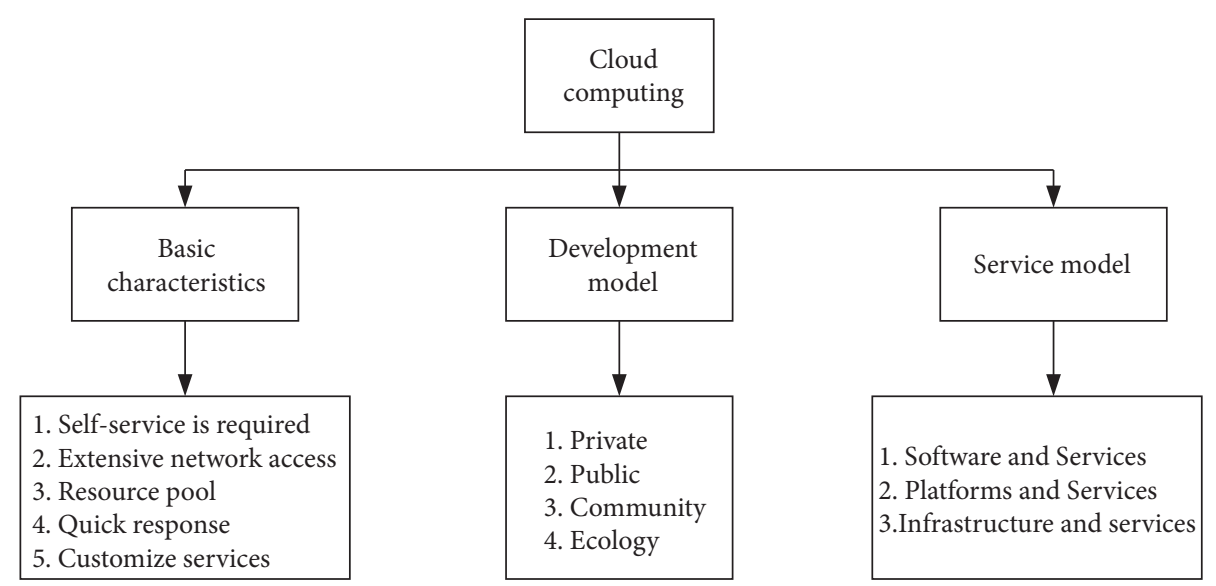

FIgURE 2: Digital technology cloud computing diagram.

2.2. Conceptual Model of Digital Technology Maturity. Digital maturity includes its digital readiness, intensity, and contribution. Among them, digital readiness includes strategic organization and infrastructure, through which digital technology is basically managed [18]. Digital intensity includes the management and integration of digital technology and improves the operation technology of digital technology through these two aspects. The digital contribution is reflected in the digital performance, through which the digital technology can be developed to a higher standard. Digital maturity is shown in Figure 3.

2.3. Promotion of Local Folk Culture. Local folk culture is a representative local folk culture formed by the gathering and mixing of people's customs of various nationalities in a region for several years. Through the folk culture of a place, we can learn about the living habits of local residents, local folk customs, and living habits [19]. Folk customs in various places nurture the local people and have an important influence on the spiritual values of the local people.

2.3.1. Protection of Folk Culture. Folk culture is an important symbol of local cultural customs, but in the continuous development of history, many folk cultures gradually declined and lost, which is the loss of local culture. We should strengthen the development of folk culture, combine folk culture with today, and strengthen people's understanding of folk culture. People should understand the history and culture of generations through the inherited folk 


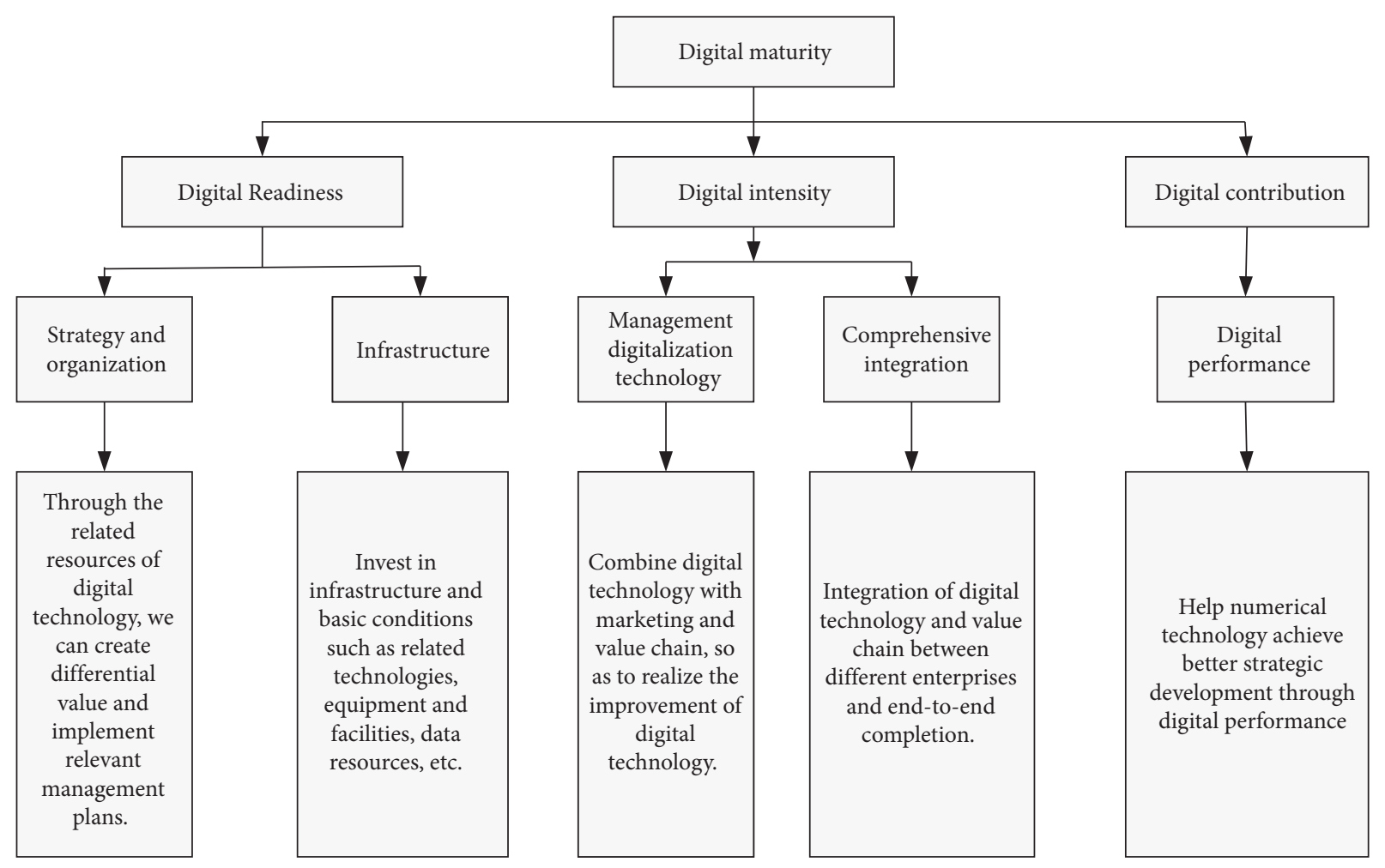

FiguRe 3: Digital maturity.

culture [20]. Therefore, we should expand the understanding of folk culture and then protect folk culture.

\subsubsection{Promoting the Cognition of Folk Culture.} Nowadays, many young people do not know enough about local folk culture and pay enough attention to it. The understanding of folk culture is limited to the cognition of living environment and parents' telling, and there are few opportunities to really contact folk culture, which leads to the existence of some people who do not understand or even know what local folk culture is. Therefore, more young people can understand and love folk culture through education and popularization.

2.3.3. Inheritance of Folk Culture. Many folk cultures have strict conditions for inheriting their culture, so special inheritors should be trained according to local folk customs. We should cultivate their cognition of local folk culture and their operation skills of folk culture [21]. Only by cultivating folk culture for a long time, can we have enough cognition of local folk culture, and can we keep inheriting national culture and not be declined.

\section{Research on Digital Technology and Visual Communication}

\subsection{Digital Technology}

3.1.1. Digital Level Measurement. $v_{i t}$ represents the original data, the maximum value of the data investigated by $v_{\max }$, and $q$ and $k$ are set by themselves in the distribution interval.

$$
X_{i}=\frac{V_{i t}-V_{\min 0}}{V_{\max }-V_{\min 0}} \times k+q .
$$

$M: x_{1}, x_{2}, \ldots, x_{m}$. There are $n$ evaluation objects in total.

$$
\begin{aligned}
\bar{x}_{i j} & =\frac{x_{i j}-\bar{x}_{i j}}{s_{j}}(i=1,2, \&, n, j=1,2, \&, m), \\
\bar{x}_{j} & =\frac{1}{n} \sum_{i=1}^{n} x_{i j}, \\
s_{j} & =\sqrt{\frac{1}{(n-1)} \sum_{i=1}^{n}\left(x_{i}-\bar{x}_{j}\right)^{2}},
\end{aligned}
$$

where $\bar{x}_{j}$ is the sample mean and standard deviation $s_{j}$ of the $J$-th index [22]. 


$$
\begin{aligned}
& R=\left(r_{\delta}\right)_{m \times m}, \\
& r_{\delta}=\frac{\sum_{k=1}^{n} \bar{x}_{k i} \cdot \bar{x}_{k j}}{n-1}(i, j=1,2, \&, m) \text {, } \\
& r_{\delta}=1, \\
& r_{\delta}=r_{j i}, \\
& \left\{\begin{array}{l}
y_{1}=u_{11} \bar{x}_{1}+u_{21} \bar{x}_{2}+\ldots+u_{n 1} \bar{x}_{n} \\
y_{2}=u_{12} \bar{x}_{1}+u_{22} \bar{x}_{2}+\ldots+u_{n 2} \bar{x}_{n} \\
\cdots \ldots \ldots \ldots \ldots \ldots \ldots \ldots \ldots \ldots \ldots \ldots \ldots \ldots \ldots \ldots \ldots \ldots \ldots \ldots \ldots \ldots \ldots \ldots \\
y_{m}=u_{1 m} \bar{x}_{1}+u_{2 m} \bar{x}_{2}+\ldots+u_{n m} \bar{x}_{n}
\end{array}, b_{j} .\right. \\
& b_{j}=\frac{\lambda_{j}}{\sum_{k=1}^{m} \lambda_{2}}(j=1,2, \&, m) \text {, } \\
& a_{p}=\frac{\sum_{k=1}^{y} \lambda_{i}}{\sum_{k=1}^{m} \lambda_{i}} \\
& Z=\sum_{j=1}^{p}
\end{aligned}
$$

3.1.2. Digital Technology Artificial Intelligence. (1) Bayesian

$$
\begin{aligned}
\mathrm{LS} & =\frac{P(E \mid H)}{P(E \mid H)}, \\
\mathrm{LN} & =\frac{P(E \mid H)}{P(E \mid H)}=\frac{1-P(E \mid H)}{1-P(E \mid H)}, \\
P(A \mid B) & =\frac{P(A \cap B)}{P(B)}, \\
P(B \mid A) & =\frac{P(A \cap B)}{P(A)}, \\
P(A \mid B) P(B) & =P(A \cap B)=P(B \mid A) P(A), \\
P\left(A_{i} \mid B\right) & =\frac{P\left(A_{i}\right) P\left(B \mid A_{i}\right)}{\sum_{j=1}^{n} P\left(A_{j}\right) P\left(B \mid A_{j}\right)} .
\end{aligned}
$$

(2) Probability function

$$
\left\{\begin{array}{l}
D(x)=\frac{P(x)}{1-P(x)}=\frac{P(x)}{P(x)}, \\
P(x)=\frac{D(x)}{1+D(x)}, \\
D(H \mid E)=L S \times D(H), \\
D(H \mid E)=L N \times D(H) .
\end{array}\right.
$$

(3) Uncertain reasoning

Evidence is determined to appear

$$
\begin{aligned}
P(E) & =1, \\
P(H \mid E) & =\frac{\mathrm{LS} \times P(H)}{(\mathrm{LS}-1) \times P(H)+1} .
\end{aligned}
$$

The evidence is determined not to appear

$$
\begin{aligned}
P(E) & =0, \\
P(H \mid E) & =\frac{\mathrm{LN} \times P(H)}{(\mathrm{LH}-1) \times P(H)+1} .
\end{aligned}
$$

3.2. Trajectory Data Visualization.

$$
\begin{aligned}
& P_{i}=\left(x_{i}, y_{i}, t_{i}\right) i=1,2,3,4, \\
& \left\{\begin{array}{l}
\text { Row }=\frac{2 y_{i}}{r} \quad i=1,2,3,4, \cdots, \\
\text { Column }=\frac{2 x_{i}}{r}
\end{array}\right. \\
& \left\{\begin{array}{l}
X=\frac{\sum_{i=1}^{n} x_{i} z_{i}}{\sum_{i=1}^{n} z_{i}} \\
Y=\frac{\sum_{i=1}^{n} x_{i} z_{i}}{\sum_{i=1}^{n} z_{i}} i=1,2,3,4, \ldots, n \\
Z=\sum_{i=1}^{n} z_{i}
\end{array}\right.
\end{aligned}
$$




\subsection{Digital KANO Model.}

$$
\begin{aligned}
\text { Better } & =\frac{(A+O)}{(A+O+M+I)}, \\
\text { Worse } & =-1 * \frac{(O+M)}{(A+O+M+I)} .
\end{aligned}
$$

Its model includes five functions, function 1 is in the second quadrant, functions 2 and 5 are in the first quadrant, and functions 3 and 4 are in the fourth and third quadrants, respectively. The first quadrant is also called one-dimensional demand, the second quadrant is also called charm demand, the third quadrant is necessary demand, and the fourth quadrant is indifference demand [23] in Figure 4.

\section{Visual Analysis of Digital Local Folk Culture}

\subsection{Analysis of Digital Technology}

4.1.1. Digital Artificial Intelligence. Through the investigation and analysis of digital artificial intelligence technology in each district, it can be seen that Region 2 ranks first with a growth rate of $379.74 \%$ and Region 1 ranks second with a growth rate of $377.51 \%$, compared with Region 5 with a growth rate of $166.08 \%$ and Region 6 with a growth rate of $123.88 \%$. Through data observation, it is known that the total index of digital artificial intelligence in Region 2 and Region 1 develops well, while that in Region 5 and Region 6 lags behind. However, according to the growth rate, it can be seen that the growth rate of the first to fifth total indexes in the regions exceeds $100 \%$, indicating that the development prospect of digital artificial intelligence is more objective in several regions surveyed, and the total growth rate has increased. Comparison of total indexes is shown in Table 1.

According to the AI environmental support, as shown in Table 2, in the growth rate ranking, Region 2 ranks first with $559.97 \%$, and Region 1 ranks second with 537.07\%. The three regions and six regions rank fifth and sixth, respectively, with growth rates of $71.15 \%$ and $59.40 \%$, respectively. According to the overall chart perception, the growth rates of Regions 1 and 2 exceeded 500\%, while those of Regions 4 and 5 remained above $100 \%$, while those of Regions 3 and 6 did not exceed $100 \%$. It can be seen from the analysis that the development of AI environmental support is unbalanced, and the development trends of the first and second regions are excellent, the fourth and fifth regions are good, and the third and sixth regions are qualified. It should be rectified according to the development methods and factors of the third and sixth regions corresponding to the first and second regions so that the growth rate of the third and sixth regions will rise greatly.

It can be seen from Table 3 that the fifth, first, second, and fourth regions rank first to fourth, respectively, and their AI industry competitiveness growth rates are $754.42 \%$, $540.41 \%, 474.33 \%$, and $404.22 \%$, respectively. The AI industry competitiveness of these four regions all exceed $400 \%$, and their development trend is excellent. However, the growth rate of the third and sixth regions is about $211 \%$, and the development trend is good. Compared with the first four

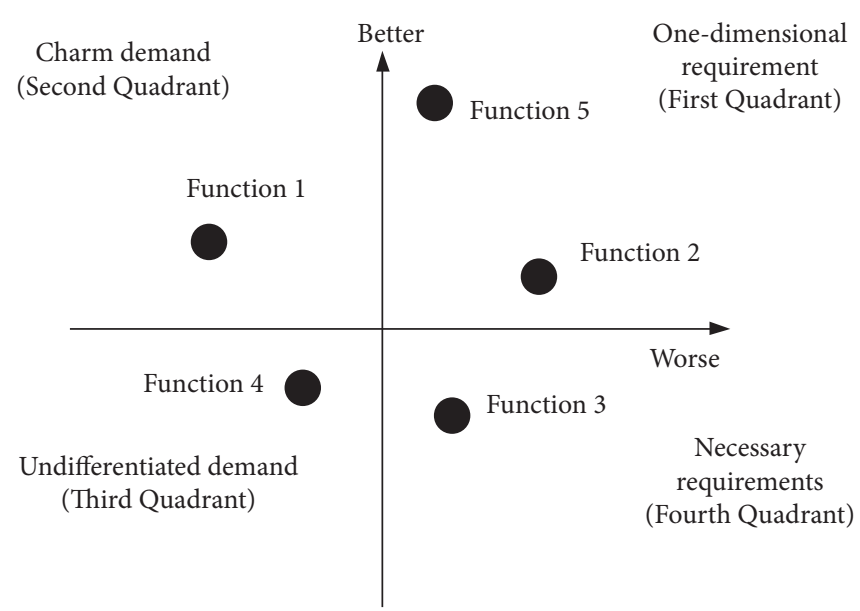

Figure 4: Quadrant diagram of KAON model.

Table 1: Comparison of total indexes.

\begin{tabular}{lcc}
\hline Rank & Growth rate (\%) & Economy \\
\hline 1 & 379.74 & Area 2 \\
2 & 377.51 & Area 1 \\
3 & 205.40 & Area 3 \\
4 & 168.34 & Area 4 \\
5 & 166.08 & Area 5 \\
6 & 123.88 & Area 6 \\
\hline
\end{tabular}

TABLE 2: AI environmental support.

\begin{tabular}{lcc}
\hline Rank & Growth rate (\%) & Economy \\
\hline 1 & 559.97 & Area 2 \\
2 & 537.07 & Area 1 \\
3 & 128.96 & Area 4 \\
4 & 117.15 & Area 5 \\
5 & 71.15 & Area 3 \\
6 & 59.40 & Area 6 \\
\hline
\end{tabular}

TABLE 3: AI industry competitiveness.

\begin{tabular}{lcc}
\hline Rank & Growth rate (\%) & Economy \\
\hline 1 & 754.42 & Area 5 \\
2 & 540.41 & Area 1 \\
3 & 474.33 & Area 2 \\
4 & 404.22 & Area 4 \\
5 & 210.92 & Area 3 \\
6 & 210.91 & Area 6 \\
\hline
\end{tabular}

regions, the development of single phase has fault phenomenon. We should study and analyze the top four regions in response to development and find the relevant influencing factors of their growth rate to improve [24].

Table 4 is a table of AI knowledge creativity growth rate. From this table, it can be seen that Region 1 ranks first with a growth rate of $165.44 \%$, Region 2 ranks second with $71.53 \%$, Region 5 ranks fifth with $-15.70 \%$, and Region 3 ranks sixth with $-35.90 \%$. In contrast, the growth rate of Area 1 is over $100 \%$, and the development trend is good, but the growth 
TABLE 4: AI knowledge creativity.

\begin{tabular}{lcc}
\hline Rank & Growth rate (\%) & Economy \\
\hline 1 & 165.44 & Area 1 \\
2 & 71.53 & Area 2 \\
3 & 27.22 & Area 4 \\
4 & 27.21 & Area 6 \\
5 & -15.70 & Area 5 \\
6 & -35.90 & Area 3 \\
\hline
\end{tabular}

rates of Area 5 and Area 3 are $-15.70 \%$ and $-35.90 \%$, respectively, which shows that its development trend is retrogressing, so we should find out the reasons from the root to make it develop positively. Comparing AI knowledge creativity table with the other three tables, we can see that its development trend is lower than its environmental support, industrial competitiveness, and total index growth rate, and its development is relatively backward, so we should pay attention to the development of AI knowledge creativity.

According to the ranking (Figure 5) of the index growth rate, compared with AI environmental support and AI industry competitiveness, its total index and AI knowledge creativity develop smoothly in each district, without largescale fault phenomenon, and develop smoothly. However, the AI environmental support has obvious fault phenomenon between regions 1 and 2 and regions 3, 4, 5, and 6, and the image is steep, which shows that the development trend of regions 1 and 2 is quite different from that of other regions. Several regions with low growth rate should refer to the development methods of regions 1 and 2 to improve their own development rate. However, the competitiveness image of AI industry is also steep, which is mainly aimed at between the three regions and the five regions. It should be adjusted for the development of this region by analyzing the regions with good development trends.

4.1.2. Age Distribution of Digital Effect. Age digitization reflects a better distribution effect map. It can be seen from Figure 6 that only about $4 \%$ of the people under 18 years old, 51-55 years old, and over 56 years old are digital audience. Its main audience is distributed in the age range of 19-50 years old, among which 19-25 years old and 36-40 years old are the majority. Through the analysis of this table, it is known that the number of people under 18 years old and over 51 years old is small. By analyzing the reasons, it can be seen that people under 18 years old and over 51 years old should share and understand their digital technology, so as to improve the audience level and perception of digital technology.

4.1.3. Educational Background of Digital Effect Audience. From Figure 7, the educational background of digital audience is mainly concentrated in high school, junior college, and undergraduate, while in primary school, junior high school, master's degree, and above, the effect of digitalization is relatively small. According to the corresponding data, digital technology should be popularized for those with primary school, junior high school, master's degree, or above, so as to comprehensively improve the audience rate of digital technology. We should make digital technology develop in all aspects.

4.1.4. Investigation on the Homework Situation of Digital Effect Audience. From this Figure 8, it can be seen that most of the audiences are enterprise staff, and there is less contact with digital technology in the work of political parties. It shows that there are many aspects that can be applied to digital technology in enterprise work, which is of great help to the work of enterprise staff and improves their work efficiency. At the same time, it is seldom used in the work of political parties, which shows that digital technology has not penetrated into all working levels. Digital technology should be popularized for jobs with less contact with digital technology to improve their work efficiency.

\subsection{Visual Analysis}

4.2.1. Comparison of Visual Loading Time. By comparing the loading time of pictures before and after visual clustering, it can be seen from Figure 9 that the maximum time before clustering is about 600 , and the minimum is about 550. After clustering, the highest loading time is about 400, and the lowest is about 290. The highest time difference between clustered and unclustered pictures is about 200, and the lowest time difference is about 260, forming a cliff-like reduction. According to the data, after clustering processing, the image is loaded by visualization, which reduces the loading time in a large area, greatly improves the loading time of visual images, and improves the loading efficiency of images.

4.2.2. Visual Efficiency Analysis Chart. Image visualization has developed from the germination of Figure 10 in the sixteenth century to the physical measurement used in the seventeenth century, image symbols in the eighteenth century, data images in the nineteenth century, modernization enlightenment in the first half of the 20th century, and the second half of the 20th century. After a long period of development, its related efficiency has been greatly improved from about $50 \%$ of the budding efficiency in the sixteenth century to about $98 \%$ now. In this slow development process, visualization technology is constantly improving, its efficiency is constantly improving, and its accuracy rate is also constantly improving [25].

\subsection{Analysis of Local Folk Culture}

4.3.1. Understanding of Folk Culture Policy. According to the random inquiry of local residents' understanding of local folk culture policies, the clarity accounted for 30\% in 2013, $35 \%$ in $2015,42 \%$ in 2017, and $48 \%$ in 2019. From 2013 to 2019 , the clarity of surveyed residents increased year by year, indicating that the inheritance and promotion of local folk culture are improving. It is completely unclear that from $10 \%$ in 2013 to $5 \%$ in 2015 to $1 \%$ in 2017 and 2019 , it has also 


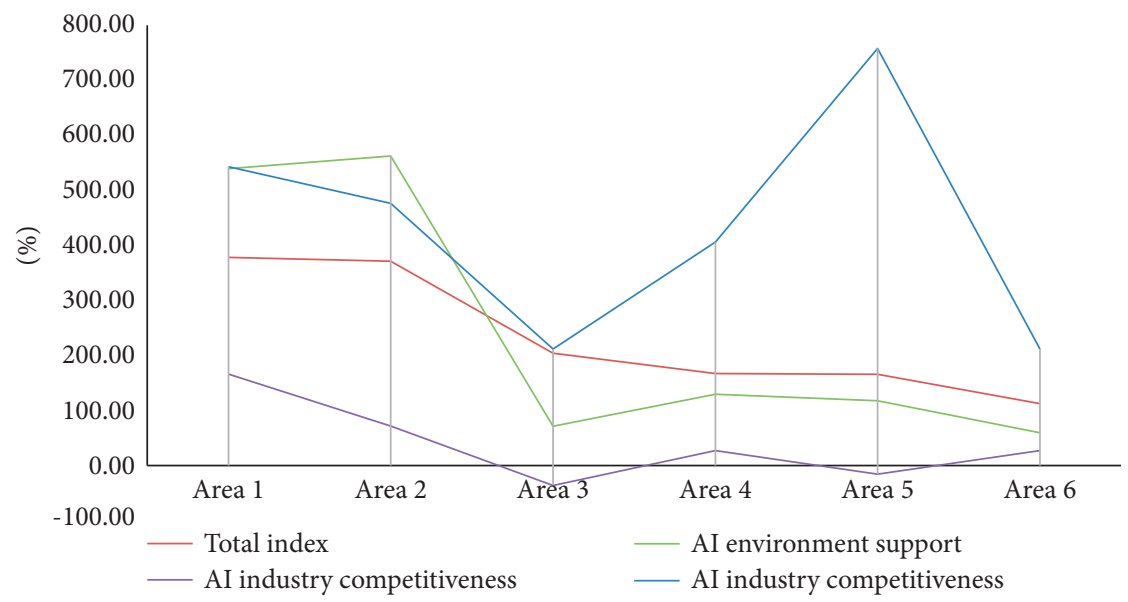

FIGURE 5: Ranking of artificial intelligence index growth rate.

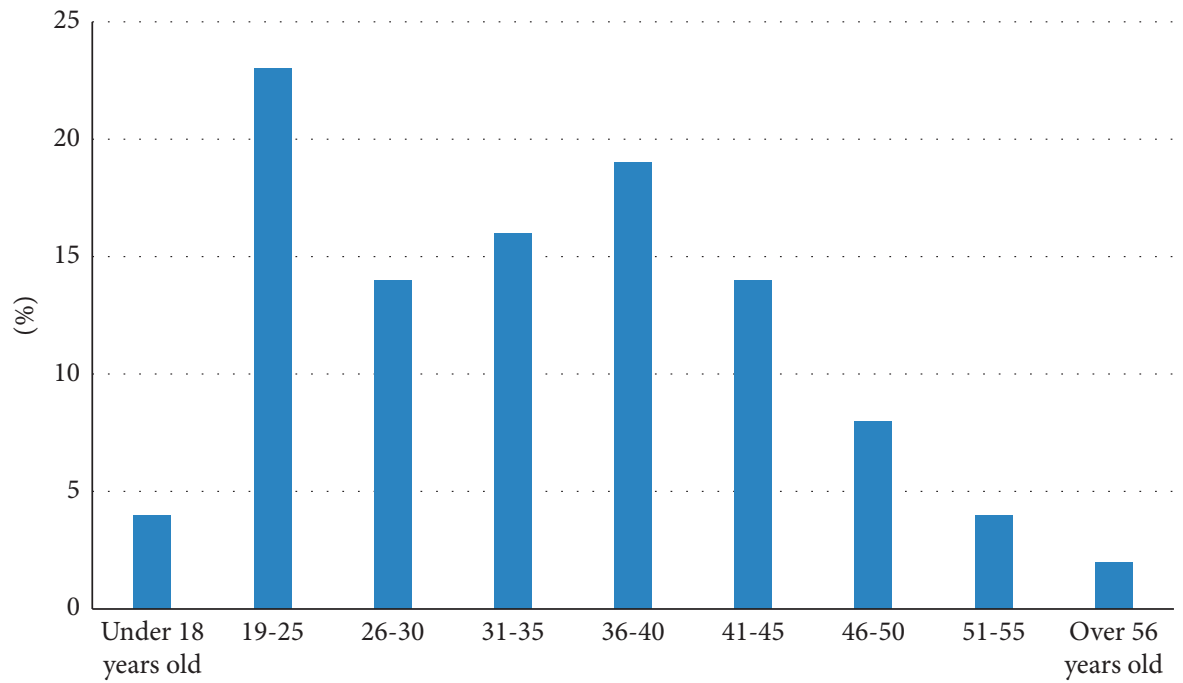

Figure 6: Age distribution of audience.

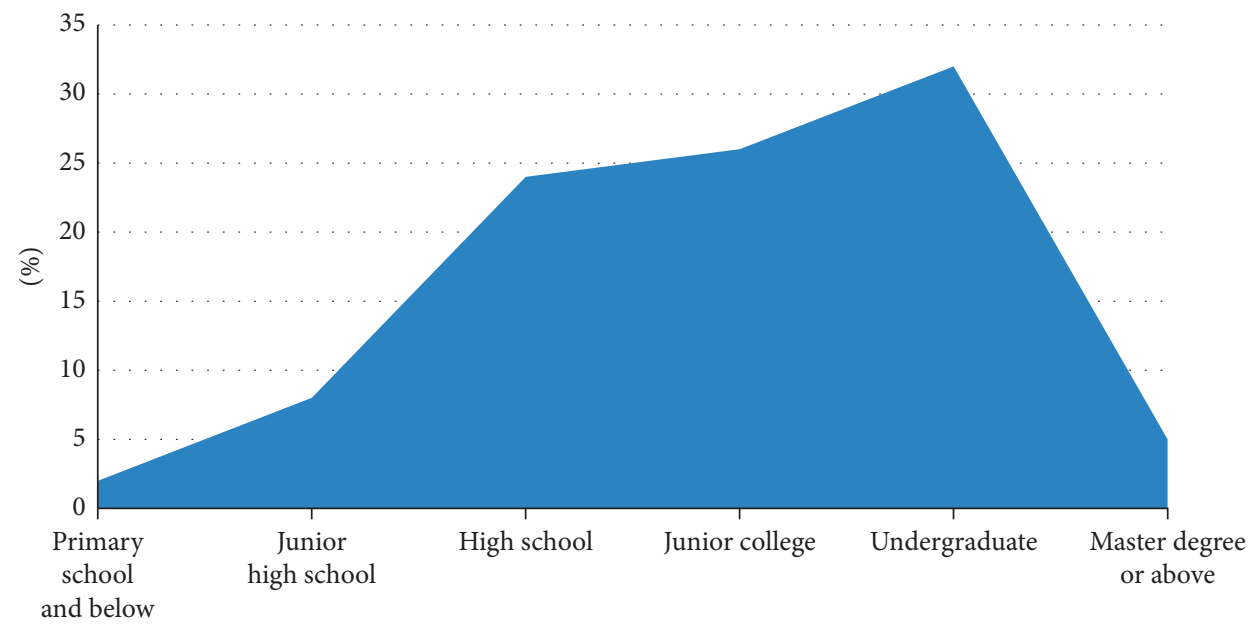

FIGURE 7: Educational background of respondents. 


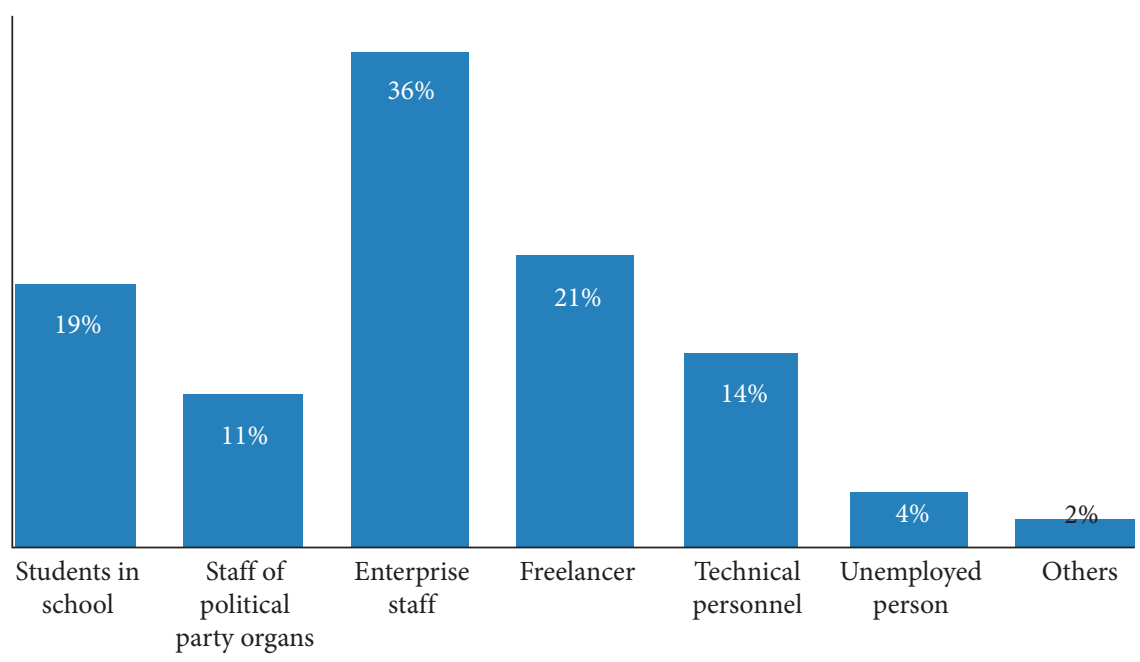

Figure 8: Survey of audience work.

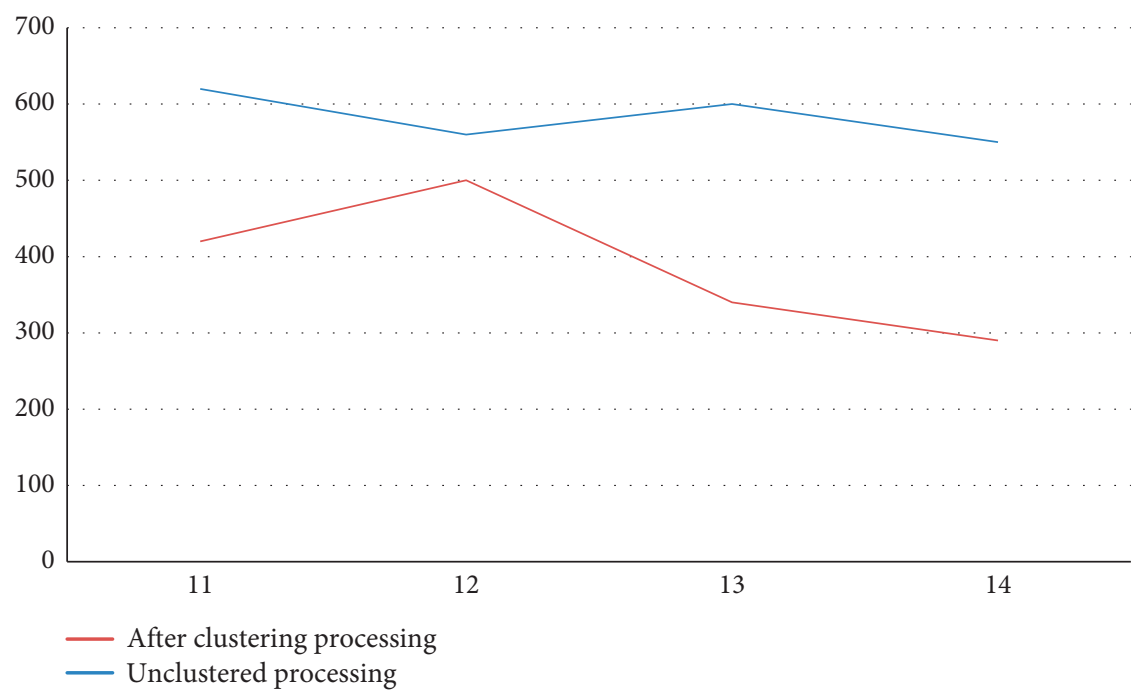

Figure 9: Comparison of image loading time.

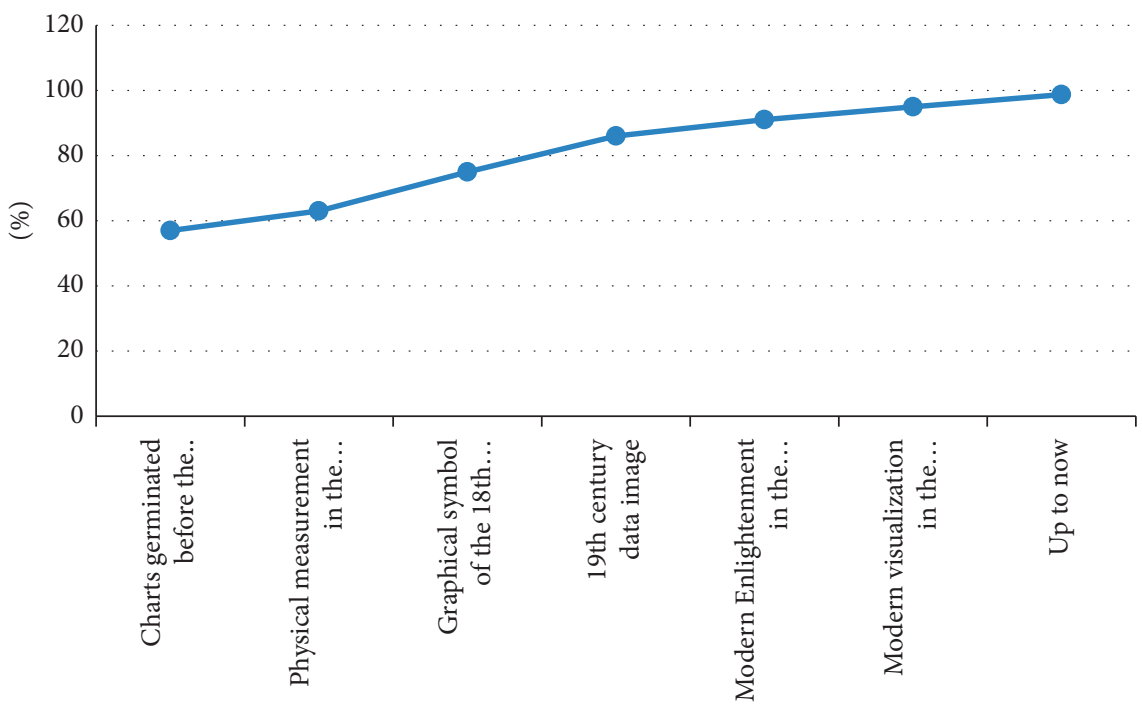

Figure 10: Visual efficiency analysis diagram. 
TABLE 5: Understanding of folk culture policy.

\begin{tabular}{lcccc}
\hline Degree & $2013(\%)$ & $2015(\%)$ & $2017(\%)$ & $2019(\%)$ \\
\hline Clear & 30 & 35 & 42 & 48 \\
Not quite clear & 42 & 36 & 28 & 12 \\
Be clear & 18 & 24 & 29 & 39 \\
Completely unclear & 10 & 5 & 1 & 1 \\
\hline
\end{tabular}

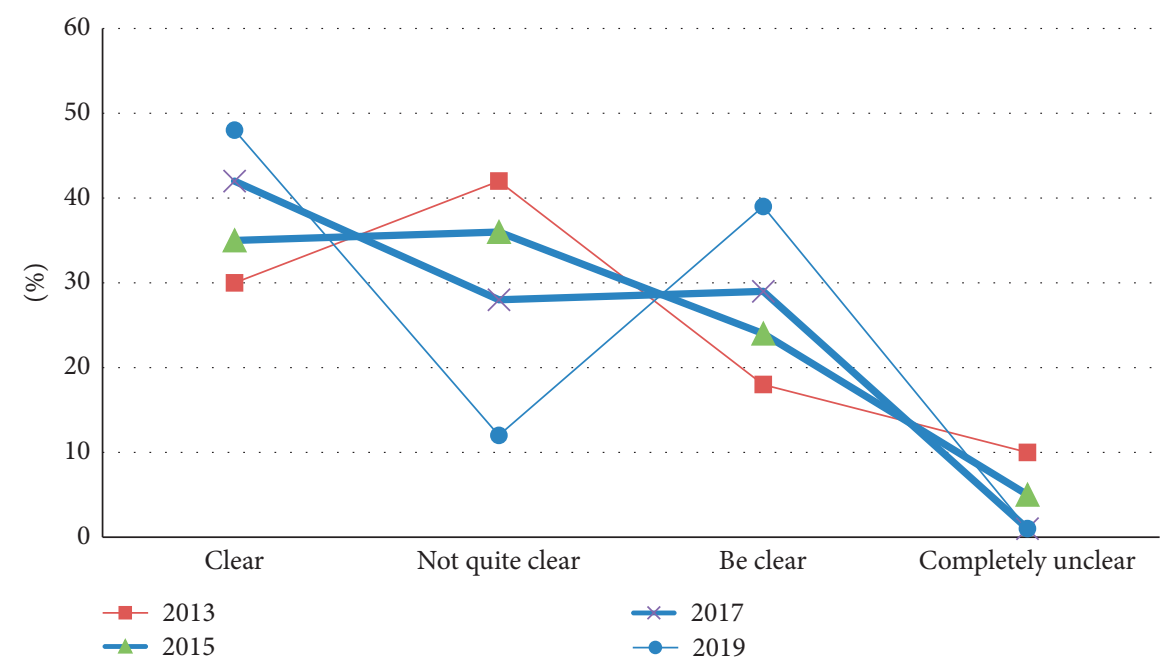

FIGURE 11: Investigation on the understanding of local folklore policy.

dropped sharply. It shows that the local people pay more and more attention to local folk culture, and their cognition of local folk culture is also improving. Understanding of folk culture policy is shown in Table 5 .

It can be seen from Figure 11 that the proportion of clarity is increasing from 2013 to 2019, the unclear and completely unclear are decreasing year by year, and the relative clarity is also increasing. From the data, we can see that the development of local folk culture has become a good development trend.

4.3.2. Insufficient Promotion of Local Culture. Through the investigation, it can be seen that the development of local folk culture mainly faces the following problems: the governance system is uncoordinated, which is mainly due to the implementation of local folk culture, the lack of proper arrangement of venues for holding activities and citizens' participation, improper coordination, and low efficiency of activity arrangement and participation. The lack of governance measures focuses on the failure to register related folk activities, provide funding for related activities, and effectively publicize folk cultural activities. The unfairness of governance means is reflected in the participants of folk culture, whether it is carried out openly, whether the safety factors are considered carefully, and whether the funds for activities are unified. The ineffective feedback of governance effect is reflected in the failure to effectively feedback to relevant management departments after rectification through the above related factors, and there are ineffective

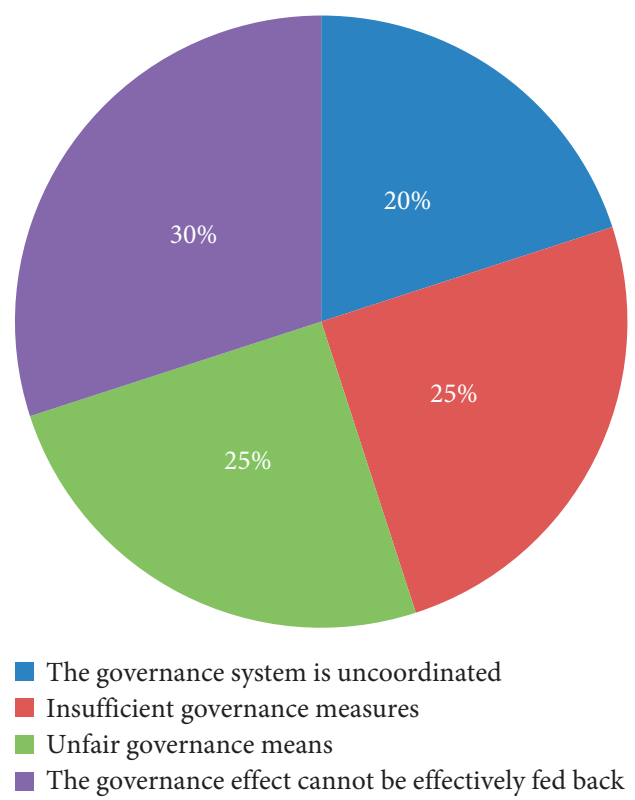

Figure 12: Insufficient promotion of local culture.

improvements, which is an unscientific and insufficient form of feedback. Insufficient promotion of local culture is shown in Figure 12.

The article shows the visual effect of folk culture communication by visualization. The data of this paper is carried out in the form of investigation, and the data are visually analyzed to analyze the current communication effect of folk 
culture in the region and the communication effect among different groups of people. The analysis results can directly show that folk culture has different communication effects in different regions, different groups, educational background, and other factors, so as to provide an effective way of communication.

\section{Conclusion}

Through the visual analysis of digital technology and local folk culture, we know that there are still some problems in the process of promoting the development of local folk culture, such as management system, governance means, and governance effect, which cannot be fed back. We should make relevant development routes through deep understanding of local folk culture, so as to protect local folk culture, promote its development, promote cognition, and inherit folk culture.

\section{Data Availability}

The experimental data used to support the findings of this study are available from the corresponding author upon request.

\section{Disclosure}

The research result of the project of Hebei Water Ecological Civilization and Social Governance Research Center: "Research on the Value and Enlightenment of Rural Social Governance in the Construction of Beautiful Villages and Characteristic Towns-A Case Study of Handan," project no. 2018SZX1.

\section{Conflicts of Interest}

The authors declare that they have no conflicts of interest regarding this work.

\section{References}

[1] W. K. Hocking, B. Fuller, and B. Vandepeer, "Real-time determination of meteor-related parameters utilizing modern digital technology," Journal of Atmospheric and Solar-Terrestrial Physics, vol. 10, no. 2, pp. 9-17, 2001.

[2] P. A. David, "Understanding digital technology's evolution and the path of measured productivity growth: present and future in the mirror of the past," Papers, vol. 8, no. 02, pp. 20-28, 2000.

[3] C. K. Blackwell, A. R. Lauricella, and E. Wartella, "Factors influencing digital technology use in early childhood education," Computers \& Education, vol. 77, no. aug, pp. 82-90, 2014.

[4] G. S. Lunney, "The death of copyright: digital technology, private copying, and the DMCA," Virginia Law Review, vol. 87, no. 5, pp. 17-32, 2001.

[5] G. S. Mort and J. Drennan, "Mobile digital technology: e," The Journal of Database Marketing \& Customer Strategy Management, vol. 10, no. 1, pp. 9-23, 2002.

[6] D. Smahel, S. Chaudron, M. E. Beutel, and M. Šmahelová, "Young Children (0-8) and digital technology: a qualitative exploratory study across seven countries," $J R C$, vol. 5 , no. 12 , pp. 26-40, 2015.

[7] R. K. Lawrence and A. T. Kelly, "Single event effect induced multiple-cell upsets in a commercial $90 \mathrm{~nm}$ CMOS digital technology," IEEE Transactions on Nuclear Science, vol. 55, no. 6, pp. 3367-3374, 2009.

[8] W. C. Slater and T. J. Murray, "Photofinishing system and method incorporating digital technology," United States Patent Application Publication, Alexandria, VA, USA, 2003.

[9] Y. L. Ning, Q. Y. Pang, and X. M. Xie, "On the role of local folk culture in cultivating socialist core values in the new era: taking the junpo festival of hainan for example," Journal of Zhengzhou Normal Education, vol. 43, no. 21, pp. 19-32, 2018.

[10] J. Liang, "The poetic imagination and theoretical construction of local folk culture:review of studies of pluralistic folk culture circle in qinghai," Northwestern Journal of Ethnology, vol. 53, no. 12, pp. 89-102, 2014.

[11] L. I. Hong-Qi, "Academies in song and yuan dynasty and local culture: Academy, academic and folk religions in jizhou region," Journal of Hunan University, vol. 34, no. 7, pp. 97-121, 2006.

[12] K. Liu and D. Zhen, "Protection and display of festival activities and local folk culture-_based on the research of shoton festival in Lhasa," Journal of Leshan Normal University, vol. 20, no. 5, pp. 17-25, 2018.

[13] M. Tanifuji, T. Sugiyama, and K. Murase, "Horizontal propagation of excitation in rat visual cortical slices revealed by optical imaging," Science, vol. 266, no. 5187, pp. 1057-1059, 1994.

[14] G. J. Qi, C. C. Aggarwal, R. Yong, and Q. Tian, "Towards cross-category knowledge propagation for learning visual concepts," in Proceedings of the Computer Vision \& Pattern Recognition, vol. 27, no. 6, pp. 103-133, IEEE, Colorado Springs, CO, USA, June 2011.

[15] Y.-C. Li, C. Strang, F. R. Amthor et al., "Parallel optical monitoring of visual signal propagation from the photoreceptors to the inner retina layers," Optics Letters, vol. 35, no. 11, pp. 1810-1812, 2010.

[16] L. Molteni and A. Ordanini, "Consumption patterns, digital technology and music downloading," Long Range Planning, vol. 36, no. 4, pp. 389-406, 2003.

[17] I. Stevenson, "Tool, tutor, environment or resource: e," Computers \& Education, vol. 51, no. 2, pp. 836-853, 2008.

[18] P. A. David, "A tragedy of the public knowledge 'common'? Global science, tellectual property and the digital technology boomerang," International Institute of Infonomics, vol. 18, pp. 1-40, 2000.

[19] L. R. Baker, "Links between local folklore and the conservation of sclater's monkey (Cercopithecus sclateri) in Nigeria," Afr Primates, vol. 8, pp. 17-24, 2013.

[20] T.-S. Yang and M.-C. Oh, "A study on impacts of selection attribute of $\mathrm{j}$ local folklore food on customers' behaviors -focusing on customer satisfaction, Re-visit, and word of mouth of jt," Journal of the Korean Society of Food Science and Nutrition, vol. 38, no. 5, pp. 636-643, 2009.

[21] E. J. Blown and T. Bryce, "The enduring effects of earlylearned ideas and local folklore on children's astronomy knowledge," Research in Science Education, vol. 54, no. 12, pp. 118-123, 2018.

[22] A. E. Miller and D. M. West, "Where's the revolution? Digital technology and health care in the Internet age," Journal of Health Politics, Policy \& Law, vol. 43, no. 2, pp. 19-27, 2009.

[23] C.-C. Chen and M.-C. Chuang, "Integrating the Kano model into a robust design approach to enhance customer 
satisfaction with product design," International Journal of Production Economics, vol. 114, no. 2, pp. 667-681, 2008.

[24] G. Dennis, B. T. Sherman, D. A. Hosack et al., "DAVID: database for annotation, visualization, and integrated discovery," Genome Biology, vol. 40, no. 3, pp. 78-99, 2003.

[25] T. Helga, J. T. Robinson, and J. P. Mesirov, "Integrative Genomics Viewer (IGV): high-performance genomics data visualization and exploration," Briefings in Bioinformatics, vol. 14, no. 2, pp. 178-192, 2013. 